\title{
Policy Measures and Safeguards to Support Natural Gas Market Liberalisation and Regulatory Reform
}

To promote the rapid and healthy development of the natural gas industry, completion and refinement of policy safeguards must take place as soon as possible.

\subsection{Create and Complete a Natural Gas Legislative Framework}

The fourth plenary session of the Communist Party Central Committee proposed the creation and completion of a legislative system, constituting a historical move towards the creation of the conditions necessary for legislative reform, laying the foundation for future legislative work. Thus legislative work should take a leading role in promoting economic and social development, which will involve a transition from "policy-guided action" to "legally guided action", ensuring that reform and legislation keep step, and that reforms occur according to the law. Only by ensuring that development of the natural gas industry is realised according to the law, and by increasingly establishing scientific and democratic legislation for the natural gas industry, can good legislation and governance be achieved, and a basic system for the

\footnotetext{
* This chapter was overseen by Xiaoming Wang from the Development Research Center of the State Council and Mallika Ishwaran from Shell International. It was jointly completed by Yusong Deng, Jiaofeng Guo, Shouhai Chen from China University of Petroleum and Qingle Wu from Shell China. Other members of the topic group participated in discussions and revisions.
}

legal regulation of the natural gas industry put in place.

Although the initial framework for a legislative and regulatory system within the natural gas sector in China is already in place, the existing legal system lacks co-ordination, consistency and systematisation. For example, China still lacks a specialist and comprehensive "oil and natural gas law" that completely covers the entire upstream-midstream-downstream production chain. In terms of exploration and development of natural gas, the existing mineral resources legislation is based on solid minerals, and deals with problems that are common to the rights issues encountered with mineral resources, making it unsuitable for resolving the specialised problems arising in relation to natural gas, a gaseous mineral. Moreover, most of the existing legislation was created for a planned economy and restricts the rules of acquisition and transfer of mineral rights and is unable to fulfil the particular needs of natural gas and market liberalisation reform. In terms of natural gas pipeline networks, the end consumer sector and environmental protection, the current regulatory legislation is incomplete, while the responsibilities and obligations of local governments and related businesses are not sufficiently clear in terms of transportation, gas storage and gas distribution. The technical specifications and standards of the modern gas industry are still not sufficiently normalised and complete.

The law is the most important tool for governing a country, and good laws are a prerequisite of good governance. To form a complete system of legal standards, first, key areas of 
legislation must be strengthened, the systematic nature of laws and regulations must be enhanced and weaknesses in the legal system causing the laws to contradict each other in terms of logic and value must be eliminated. Therefore, the legal framework of the natural gas industry should be improved as soon as possible. There should be a comprehensive and effective natural gas legal framework that consists of legislation specific to the natural gas industry, with an "oil and natural gas law" at the core.

Improving the application of such legislation will make it better suited to the characteristics of natural gas exploration, production, transportation, storage, distribution and usage. Completion of improvements to relevant implementation rules and supporting regulations should come first. Gas-specific legislation should be established as soon as possible, consisting of the formulation or revision of the "oil and gas mining rights regulations", "natural gas midstream and downstream administrative regulations", "gas extraction environmental protection regulations", "offshore oil and gas pipeline protection regulations", "natural gas reserves regulations" and other administrative regulations. Improvements to legislation in relation to resource rights, exploration and development contracts, infrastructure and operational management, storage, sales and usage, safety alerts and emergency response, production safety and compensation for environmental impact, cross-border investment and import and export trade are all vital as well.

Administrative regulations for natural gas midstream and downstream should be researched and drafted. The regulations should include, at the very least: supervisory participants and duties at different levels of government; the organisation, position, powers, duties, regulatory principles and operating mechanisms of a natural gas regulatory body; natural gas transportation administration modes and operational mechanisms; the rights, obligations and responsibilities of businesses in relation to natural gas; the principles and mechanisms which will determine the prices and distribution charging rates for natural gas; pipeline construction and authorisation; maintenance, security and open access to pipelines; and resolution of disputes.

Environmental protection regulations for gas extraction should be researched and formulated. Special provisions must be made for the following aspects of natural gas exploitation: pollution prevention planning; environmental impact assessments; pollution permits; drilling fluids and exhaust gases; the recycling or processing of waste water and toxic gas; noise control; management of radioactive sources; environmental monitoring; excessive pollution; and emergency response to pollution incidents.

Areas of conflict between the oil and gas pipeline protection law and other laws should be dealt with through by legal interpretation. There are various urgent needs: co-ordinating pipeline development planning and other specific planning; dealing with the convergence between pipeline construction planning and urban and rural planning; legal determination of underground pipeline passage rights; restrictions on land use in relation to pipeline safety; and conflicts between pipeline safety and road and rail safety requirements.

\subsection{Deepen Reform of Oil and Gas Regulations}

The existing energy administration systems must be rationalised, and this will involve a gradual transition to a high-level, centralised energy administration. Industry administration should be enhanced by placing general industry-focused planning, market access approval and legislative functions under the control of one overall department. More emphasis should be placed on strategic planning in relation to energy development, implementing comprehensive planning, policies and standards in the administration of the industry. Increasing the rate at which related governance is simplified and deregulation occurs, further removing and deputising various administrative duties and application approval 
functions, and making a clearer distinction between the role of government and the role of business, will reduce the extent of government interference in microeconomic affairs. The separation of government and business functions should be promoted further by separating naturally monopolistic businesses from competitive businesses, and opening up specific areas to competition, encouraging orderly access for all types of investor to all areas of the energy industry, to allow fair access and encourage effective competition.

Admission management should be implemented using a restriction list. A "restriction list" is a government-compiled list of fields, businesses etc. to which prohibition or restrictions apply. Access to fields that are not included on the list is completely open, as a principle of "permissible unless prohibited" applies. Give full play to the market's decisive role in resource allocation, and ensure that where control is released this occurs effectively and reduces admission thresholds. If not prohibited by law, activities should be open to market participants. If not authorised by law, government activity in activities is not permitted. This will provide greater space for the market to play a determining role. A unified market admission system should be implemented, founded on a restriction list regime, encouraging and guiding the access of various types of market entity to participate in fields other than those listed in the "restriction list" in accordance with the law. This will promote diversification of investors in the energy sector.

However, in addition to relaxing market admission, there should also be certain large, significant changes involving deregulation of both large and small enterprises. For example, in the oil and natural gas development and infrastructure fields, where problems related to administrative monopolies are particularly pronounced, allowing access to one or two major competitors will result in more effective competition. Consideration could be given to tendering and bidding for conventional oil and gas mineral rights for the Sichuan Basin pilot scheme, to the release to competition of construction and operation of the provincial pipelines and to the complete deregulation of the oil and gas markets for Sichuan, Chongqing and other cities. Deregulation of oil and gas importing would open up both domestic and foreign markets and allow private enterprises to grow in influence.

\subsection{Deepen Reform of the Fiscal and Tax Systems}

\section{Further improve fiscal policy}

Action should be taken to take advantage of market effects so as to expand funding for geological exploration, with a focus on supporting and promoting unconventional and deep water natural gas resource development and international co-operation. Government support mechanisms for fundamental, strategic and cutting-edge scientific research and research into generic technology and mechanisms for funding major equipment should be improved. The peak regulation, frequency modulation back-up and compensation policies should be refined.

The manner in which taxes are divided between central government and local government needs adjusting. When compared to thermal power generation and other such traditional energy sources, the financial discounts applied to natural gas and other clean energy sources offer few benefits in terms of local fiscal income, and as a result there is little stimulus for activity in this area in local government. On the other hand, when compared to central taxes, the sources of local taxes are fairly dispersed, while collection and administration presents greater difficulties, with unstable income affecting funding for the development of natural gas by local governments. We suggest an appropriate adjustment of the proportions of VAT, company income tax and other taxes allocated from the natural gas sector, increasing local government fiscal income, which will act as an encouragement to local government to develop natural gas. 


\section{Extension of financial subsidies for shale natural gas}

Efforts to provide policy support for coalbed methane as soon as possible should be intensified. Financial subsidies to coalbed methane development companies should be increased to $0.60 \mathrm{CNY} / \mathrm{m}^{3}$. The corporation tax exemption policy should be extended to 2020, and there should be strict implementation of the VAT refund policy or implementation of an "immediate refund" policy.

Between 2012 and 2015, China's central government gave a standard subsidy of 0.4 $\mathrm{CNY} / \mathrm{m}^{3}$ to shale natural gas businesses who satisfied the relevant conditions. The period to which the 13th Five-Year Plan applies will be critical for the launch, development and growth of China's shale natural gas industry. Encouragement of exploration and development of shale natural gas will continue, despite the sharp drop in international oil prices and the likelihood that these will remain at between 60 and $80 \$ /$ barrel for the next 3-5 years and the associated reduction in global investment in shale natural gas. In light of this, the continuance and implementation of further shale natural gas exploration subsidies is of major importance if shale natural gas is to continue to be developed on a large scale in China. The standard subsidy for 2016-2018 is currently $0.3 \mathrm{CNY} / \mathrm{m}^{3}$; the standard subsidy for 2019-2020 is $0.2 \mathrm{CNY} / \mathrm{m}^{3}$.

\section{Accelerate resource tax reform}

The objective of resource tax reform should be the promotion of the rational development and utilisation of natural resources, the promotion of ecological and environmental protection and the acceleration of transformation of development modes. It should be introduced in three stages and cover three areas. In 2015-2016, preliminary completion of a resource tax system; in 20172018 the resource tax system should be more or less completed; and in 2019-2020 the objective of the resource tax reforms should have been fundamentally achieved, leading to an emphasis on establishing the application of resource tax, determining appropriate taxation levels and extending the scope of tax collection, improving calculation and collection methods, and refining a system of resource commodity pricing, this being achieved via integrated measures.

Research should be carried out on adjusting petroleum product consumer taxation systems and tax rates, promoting petroleum product consumer tax reform using multifaceted taxation schemes. On the basis of improving the existing tax system, multifaceted collection schemes are recommended, promoting petroleum product consumer taxation reform. First, strict accreditation of wholesale businesses should be applied, through channels such as media monitoring and public oversight, to ensure that access is provided openly, fairly and justly to approved wholesalers. Second, tax departments should focus on a new tax collection scheme, adjusting the regulatory focus to ensure that the transition between the old tax system and the new one is smooth and successfully implemented. Third, the proportion of oil consumption tax to be shared between local and central government should be determined in a scientific manner, encouraging the active involvement of local government in collection and administration. Fourth, thorough monitoring and improvement systems should be put in place in order to deal with new problems and situations which arise with the new tax system.

\section{Establish and improve environmental tax and carbon trading policy systems}

Environmental taxes are taxes levied for environmental purposes and include special taxes imposed or levies imposed as a form of preventing pollution or damage to the environment. The scope of such taxes ensures that they are levied against and specifically target behaviour harmful to the environment. This form of taxation (also known as "independent environmental 
taxation") is thus intimately connected with environmental protection, and generally includes pollutant emission taxes, contaminant taxes and carbon taxes. Pollution emission taxes are environmental taxes levied against pollutant emissions (such as waste gas, contaminated water and solid waste). Contaminant taxes are environmental taxes levied against potentially contaminating products (such as energy fuels, motor vehicles, ozone-depleting substances, fertilisers, pesticides, detergents containing phosphorous, mercury-cadmium batteries). Carbon taxes are environmental taxes levied against carbon dioxide-generating fossil fuels such as coal, oil and natural gas.

During the period of the 12th Five-Year Plan, encouragement was given in particular to the breakthrough in carbon trading which encouraged pilot schemes to realise a move from "voluntary trading" to "mandatory trading". In the long term, the aim is to establish a comprehensive primary and secondary market which covers the entire economy and which integrates international markets, with market mechanisms playing a decisive role in the optimised allocation of all kinds of energy efficiency and emissions reduction resources, in order to achieve maximum emissions reduction for minimum cost. Regarding carbon tax, carbon tax legislation should be accelerated, making it possible to think about ways in which carbon trading can be used in conjunction with carbon taxes, thus allowing implementation of a variety of policies. At the same time, enterprises which actively use emissions reduction and carbon dioxide recovery technology and which reach certain standards should be given tax breaks.

Legislative work in relation to the transformation from an environmental charge to an environmental tax system and the introduction of pollutant emissions taxes should be accelerated. The objects of existing charges levied on pollutant emissions should all be included in the scope of the pollutant emission taxation, and comprehensive reform of the pollution charging system should be implemented. Further refinement of energy efficiency and emissions reduction taxation policy is required, as is the creation and refinement of an environmental compensation mechanism, while the possibility of implementing a green tax system should be explored.

\subsection{Establish and Complete a Natural Gas Data Management System}

Refinement of a unified information management system should occur as soon as possible. Submission of oil and gas data should be linked directly with mineral rights administration, allowing comprehensive integration and data sharing in the mineral rights administrative processes. Accelerate the establishment of a national database. The main areas covered by this should be the results of domestic oil and gas geographical surveys and data relating to exploration and development, covering both domestic and foreign oil and gas resource data. Establish a national public information network for oil and gas resources, implementing concentrated and dynamic, publicly accessible data, mineral rights administration and raw data in an integrated oil and gas data management, publication and sharing service platform, in order to effectively promote an open-door policy on mineral rights, with truly equitable access, thus encouraging effective competition.

\subsubsection{Data Submission}

Various types of data related to the exploration and development of conventional natural gas, shale natural gas and coalbed methane, including original geological data, outcome data and relevant geophysical information from geological work, should be submitted to the departments responsible for management of state-owned land resources, which will then be filed with the natural gas mineral rights administration. Original 
geological data and results data to be submitted should include specialised information of aspects such as field geology, geophysics, geochemistry, geological remote sensing, experimental testing, engineering geology, drilling engineering and information technology. The complete dataset for the previous year should be submitted by the second quarter for the previous year.

\subsubsection{Standardised Data Management}

To strictly regulate the resource-based integrated data management of conventional natural gas, shale natural gas and coalbed methane, submission of natural gas resource raw data will be linked with gas mineral rights administration. This will establish mechanisms for natural gas resource data acquisition, processing, management and storage, promote the digitisation of natural gas resource raw data and establish and improve new mechanisms for natural gas resource raw data management and services, creating an integrated management and shared services platform for natural gas resource raw data.

\subsubsection{Database Development and Information Disclosure}

Resource information covering domestic conventional natural gas, shale natural gas and coalbed methane should be set up, adopting China's natural gas resource survey and exploration and development data as the basis of the main content of a national gas resource database. Implement comprehensive integration and data sharing in relation to the natural gas mineral rights administrative processes. Create a national public information network for oil and gas resources, implementing unified natural gas resources information management of concentrated and dynamic data, public data, mineral rights administration and raw data.

\subsection{Increase Reform and Technical Innovation in the Natural Gas Sector}

State investment in gas development and utilisation technology should be increased. The focus should be on key technological breakthroughs, increasing investment in the areas of key technology common to unconventional gas exploration, deep water gas development and LNG storage and transportation. Strategic planning and expansion of research and development should be instituted in the following eight key technology areas: shale natural gas exploration, deep water gas development, coalbed methane extraction, gas hydrates extraction, coal-based methane, gas-powered vehicle (and ship) engine manufacturing, combined cycle gas turbine generators and carbon capture and storage, with a focus on achieving key technological breakthroughs and early deployment of fundamental research in the relevant fields.

The administrative system in relation to existing technological investment needs to be reformed. The national energy departments should organise and co-ordinate scientific, territorial resource, industry and information, finance, environmental protection and standardisation departments, defining the tasks and responsibilities of each different department with respect to support for natural gas technology innovation. With leadership from the State Council, uniform supportive policies should be developed according to the shared features of technology. Recommendations for improving the support system for natural gas technology innovation include:

- Establish a national major technology laboratory for unconventional gas, providing manpower, resources and finance for research breakthroughs relating to key technology, should be established.

- Support business innovation and enhancing industrial technological capabilities.

- Support businesses to transform themselves and upgrade to clean, gas-based energy. 
- Improve production efficiency through technological innovation and investment.

- Assist backbone enterprises in adopting core technology, thus enhancing their technical capabilities and establishing their core competitiveness.

- Strengthen the links between producers and academic research.

- Support research into shared technology and develop and implement independent projects promoting autonomous, localised projects relying on clean gas based energy equipment.

- Encourage localised manufacturing of clean, gas-based energy technology.

- Intensify efforts to train personnel, supporting the establishment of corporate research and development centres and post-doctorate research centres.

- Strengthen shale natural gas geological research, and accelerate the development and application of "factorisation" and "complete sets" in the adoption and development of technology.

- Explore the formative process involved in the development of advanced practical shale natural gas exploration and development technologies and business models.

- Foster in-house innovation and equipment manufacturing capacities.

- Encourage joint scientific advances and international co-operation, ensuring the introduction, digestion, absorption and innovation of advanced technology.

- Adopt shale natural gas exploration, development and production technology suited to China's surface and subsurface geology.

- Accelerate the formation of environmentally friendly and cost-effective key technology and equipment systems specific to China and implement these in order achieve widespread adoption.

In terms of equipment, the first step should be to increase the power rating of technology, reducing the number of devices necessary and reducing the footprint of well-sites, making them more suitable for mountainous settings. Next, the aim should be to bring about equipment modularisation, miniaturisation and portability so as to facilitate work in complex surface configurations. To achieve cost reductions, design process optimisation and research into low-cost hydraulic fracturing options should be actively pursued. As regards environmental issues, environmental protection and the safety of additives should be ensured, as should co-ordinated resource development and environmental protection. Over the next 3-5 years, at the same time as digestion, absorption and innovation technologies are introduced, key shale natural gas engineering technology installations systems with Chinese characteristics should be adopted on a wider scale, and these should be environmentally friendly, economical and effective. After 2020, efforts should be made to ensure that localised and mature proprietary shale natural gas technology and equipment is available.

Large-scale coal gasification and methanation equipment, energy efficiency cascade technology improvements, microalgal biodiesel technology as well as key sewage treatment technologies should be given priority and included in key national basic research projects, while there should be increased investment in the development of technology and applications. Relying on existing model coal methane projects, further innovation and research should take place concerning the suitability of coal types and high-pressure gasification, increasing production capacity, improving gasification, reducing water consumption, promoting environmentally friendlier new-generation coal gasification techniques and key equipment and other such breakthroughs in proprietary innovations. In addition, research and development of high-temperature methanation synthesis and reactor technology and equipment should take place, gradually resulting in the creation of core production technology and automated integrated systems suited to the characteristics of Chinese coal. 
Research efforts into gas hydrates exploration and development technology should be ramped up, enhancing the research and development capabilities in relation to core technology, thereby encouraging the development of core technology intellectual property.

- Investigation and evaluation of gas hydrates will provide a basis on which the orderly development of gas hydrates can take place. Further improvements in resource surveying, exploration and evaluation techniques should be applied to gas hydrates, prioritising prospecting criteria and methods, allowing the distribution of China's maritime and tundra gas hydrates resources to be plottedthis will establish which gas hydrate land areas are commercially viable.

- Strengthening scientific and technological research into extraction technology will promote a process by which gas hydrates could be developed in China. This should mainly include:

- research into methods that result in rapid and efficient decomposition of gas hydrates, such as depressurisation, heating, chemical inhibition and carbon dioxide substitution;

- research into key technology such as drilling, completion, cementing, horizontal wells and fracturing and improved gas collection, storage and transportation technology, which will establish a relatively complete gas hydrates extraction technological system;

- research and development into extraction equipment and other key equipment, encouraging the introduction of locally manufactured gas hydrates extraction equipment, enhancing the technical level of China's gas hydrates extraction equipment, strengthening the integration of extraction techniques and methods, optimising extraction schemes and equipment portfolios, and formulating practical gas hydrates development technological systems.
- Strengthening research into extraction safety and environmental assessment, in order to establish the likely impact of gas hydrates extraction on global climate change, seabed geological disasters and deep-sea ecosystems as soon as possible, will allow the introduction of appropriate dynamic monitoring, disaster warning and control systems.

\subsection{Expand International Energy Co-operation}

Co-ordinate the use of domestic and international resources and markets. Particular attention should be paid to ensuring that investment and trade go hand in hand, while making use of both land-based and maritime channels, in addition to accelerating the development and implementation of mid-term to long-term planning in relation to overseas energy resources, focusing on expanding import channels, building the Silk Road Economic Zone, the 21st Century Marine Silk Road, the BCIM Economic Corridor and the Pakistan Economic Corridor, and actively supporting energy technology, equipment and engineering teams to "look outside".

Strengthen the construction of the five key energy co-operation regions of Russia and Central Asia, the Middle East, Africa, the Americas and Asia-Pacific, and deepen bilateral and multilateral international energy co-operation to establish regional energy markets. Actively participate in global energy governance. Strengthen co-ordination and encouragement of enterprises to "look outside" and to acquire or obtain shares in foreign companies dealing with advanced shale natural gas and other unconventional gas development technologies in a systematic and targeted manner, allowing China to accumulate technological experience relating to unconventional gas development.

- Further optimise the authorisation process to improve authorisation efficiency. Competition for international oil and gas resources in the 
mergers and acquisitions market has been relatively intense. Good projects often receive a lot of attention, while requirements relating to deadlines have become stricter. In light of this, it is recommended that the relevant departments tighten up their overseas investment authorisation procedures, reducing risks where possible and increasing authorisation efficiency in order to shorten the time required for authorisation to be granted.

- Take effective measures to solve the problem of the shortage of investment and financing for overseas corporate mergers and acquisitions. First, policy banks can give the necessary support to enterprises for acquisition financing. Second, China Investment Corporation may be able to act as an investor for certain projects. Third, some China-Africa development funding and other such equity investments can play a role in overseas investment.

- From the long-term perspective, it is necessary to build a policy system which will encourage oil companies to "look outside". First, co-ordinate the development of national oil security strategy and energy diplomacy policy, creating an international environment which is conducive to overseas investment in oil and gas, such as signing of investment protection agreements, securing relatively reasonable fiscal terms on resources in regions like Latin America and Central Asia and refinement of the government's mechanism for rapid response to overseas emergencies. This will minimise the political, security and policy risks faced by oil companies due to overseas investment. Second, establish overseas venture exploration funds for projects approved by the state for which oil companies can apply; after high-risk exploration pays off, a share of the proceeds is returned, or partly written off in the case of failure.
At the same time, the oil and gas futures market being created in China must take into consideration the status and trends of the distribution of global resources, production development, trade flow and increasing consumption. A perfect, modern, international oil and natural gas market system with foundation like these will help China attain a relatively favourable position in the process of using global oil and natural gas resources to develop its economy. Therefore, on the one hand China should respond to the developments and trends in the market while improving the domestic oil circulation system and price formation mechanisms, in order to establish an oil and natural gas industrial system based on diversified natural gas resources, diversified participants and open-market prices. On the other hand, though satisfactory market admission, foreign currency and customs policies must be put in place, in order to attract a large number of international investors to participate in building a global international oil and natural gas futures market.

The establishment of the China (Shanghai) free trade test area (the FTA) provides the conditions necessary to develop a Chinese oil and natural gas futures market. Organisations such as the People's Bank of China have issued policies such as Suggestions on the Financial Support of the Shanghai FTA, under the principles of "first release, then regulate" and "controllable risk, steady progress". Capital account convertibility, CNY cross-border use and interest rate market liberalisation have already been achieved in the FTA, indicating that China has entered a new stage of financial innovation and that the establishment of an offshore financial market has already begun. Moreover, the Shanghai international energy trading centre will be specifically responsible for the construction of an international oil and natural gas futures platform, contract design and supporting mechanisms (such as foreign investor participation in transactions and 
bonded delivery), thus establishing a market trading system based on three main principles: value-changing mechanisms, fair trading rules and good credit systems. Solid progress on this work indicates that China expects to launch international oil and natural gas futures trading in the near future, an event which will attract the participation of large numbers of international investors, which will allow us to take better advantage of both domestic and international resources and markets. This will in turn help to improve the international competitiveness of Chinese oil and gas companies on the open market, promoting the establishment of a Chinese oil and natural gas market system that is able to meet the ever-growing economic and social development needs for energy while ensuring national energy security.
Open Access This chapter is licensed under the terms of the Creative Commons Attribution 4.0 International License (http://creativecommons.org/licenses/by/4.0/), which permits use, sharing, adaptation, distribution and reproduction in any medium or format, as long as you give appropriate credit to the original author(s) and the source, provide a link to the Creative Commons license and indicate if changes were made.
The images or other third party material in this chapter are included in the chapter's Creative Commons license, unless indicated otherwise in a credit line to the material. If material is not included in the chapter's Creative Commons license and your intended use is not permitted by statutory regulation or exceeds the permitted use, you will need to obtain permission directly from the copyright holder. 